\title{
Miscellany
}

\section{Bursary commemorating Dr Christine Cooper}

Applications are invited for a bursary commemorating the life and work of Dr Christine Cooper. A sum of up to $£ 600$ is available to further the interests of an individual or a group working in the field of child abuse or neglect.

Applications should be made before the end of January 1990 to Professor A. Aynsley-Green, Head of the Department of Child Health, The Medical School, Framlington Place, The University, Newcastle upon Tyne NE2 4HH. These should outline (maximum 500 words) the proposals for the use of the bursary and the benefits which the applicant hopes to derive from it.

\section{British Epilepsy Association}

The British Epilepsy Association celebrated the first anniversary of its National Information Centre and Epilepsy Helpline on 26 September 1989. The Centre provides confidential advice and expert information on any aspect of epilepsy. Further information can be obtained from Lesley Wood, British Epilepsy Association, Anstey House, 40 Hanover Square, Leeds LS3 1BE. The Epilepsy Helpline telephone number is 0345089599 (all calls charged at local rates).

\section{Curt P. Richter Prize in Psychoneuroendocrinology}

The International Society of Psychoneuroendocrinology invites submission of manuscripts for the Curt P. Richter Prize for 1990. The manuscript should describe original research in the field of psychoneuroendocrinology. To be eligible, an author must be less than 40 years old on 1 January 1990 . The award includes an honorarium of $\$ 1,000$ (US). Submissions will be screened by a committee of the Society and the prize awarded at the 1990 meeting of the Society in Buffalo. The winning paper will automatically be considered for publication in Psychoneuroendocrinology. The deadline for submission is 31 January 1990.

For further information regarding submission of manuscripts, please contact: Professor Jean J. Legros, Psychoneuroendocrinology Section, CHU (B23), Sart Tilman, B-4000 Liège, Belgium.

\section{British Association of Psychotherapists}

The British Association of Psychotherapists (Jungian, Child and Freudian Sections) has been providing training with an analytical orientation since 1963. Applications are invited for professional training to any of the three sections from graduates or qualified practitioners with appropriate experience in health, psychology or the social services. The Freudian Section also invites applications from child psychotherapists wishing to obtain an additional qualification in adult psychotherapy. Training is part-time and evening-based and there are opportunities for students to participate in regular scientific meetings and conferences with all sections of the Association. Further details and application forms: Mrs Judith Lawrence, Secretary, BAP, 121 Hendon Lane, London N3 3PR (telephone 01346 1747). (see also Forthcoming Events).

\section{Independent assessment and guidance in education}

Psychiatrists working with children and adolescents may be interested to hear of a new diagnostic and advisory service provided by a team of experienced psychologists. Services range from detailed assessments to supportive work in schools. For a brochure and further information contact: The Administrative Secretary, Child Consultants, 3 Devonshire Court, 26a Devonshire Street, London W1N 1 RJ (telephone 01935 9659). 